\title{
High strain rate characterisation of soda-lime-silica glass and the effect of residual stresses
}

Martin Jensen Meyland ( $\nabla$ majeme@byg.dtu.dk)

Technical University of Denmark: Danmarks Tekniske Universitet https://orcid.org/0000-0003-47246676

Jens Henrik Nielsen

Technical University of Denmark: Danmarks Tekniske Universitet

\section{Research Article}

Keywords: Float glass, Thermally tempered glass, Flexural strength and stiffness, Dynamic material characterisation, Digital image correlation, Split-Hopkinson pressure bar

Posted Date: February 10th, 2022

DOI: https://doi.org/10.21203/rs.3.rs-1317618/v1

License: @ (i) This work is licensed under a Creative Commons Attribution 4.0 International License. Read Full License 


\section{High strain rate characterisation of soda-lime-silica glass and the effect of residual stresses}

Received: 1 February 2022 / Accepted: / Published online:

Abstract A ring-on-ring test configuration for the equibiaxial flexural testing of flat samples was developed and integrated into a novel modified split-Hopkinson pressure bar (SHPB) setup. The established modifications enabled the application of high-speed cameras for fracture assessment and non-contact displacement measurements using stereo digital image correlation (stereo-DIC). In the present paper, this setup was utilised to characterise the flexural surface strength and stiffness (Young's modulus) of circular, as-received sodalime-silica glass samples at high strain rates. The effect of residual stresses was also studied by including thermally tempered glass samples divided into four residual stress groups. Despite the frequent application of glass products in the built environment, often post-processed into tempered or laminated glass, these investigations are still rare and thus highly demanded when designing for extreme events such as extreme weather, ballistic impacts, or blast loads. A total of 315 samples were tested at a quasi-static and a dynamic loading rate ranging from $2.0 \mathrm{MPas}^{-1}$ to $4.2 \cdot 10^{6} \mathrm{MPa} \mathrm{s}^{-1}$. It was found that the flexural strength of the glass across residual stress groups was strongly dependent on the applied dynamic loading rate, while the residual stresses themselves showed no significant effect on the loading rate dependency. At the dynamic loading, the strength increased between 60 and $86 \%$. Within the two tested loading rates, strength increased expectedly with compressive surface stress. From the stereo-DIC displacement measurements, no change in Young's modulus with loading rate was observed.

Keywords Float glass · Thermally tempered glass $\cdot$ Flexural strength and stiffness · Dynamic material characterisation . Digital image correlation - Split-Hopkinson pressure bar

\section{Introduction}

Soda-lime-silica glass (SLSG) is a linear elastic, brittle material that exhibits time-dependent strength characteristics. Essentially, the strength is governed by surface defects that grow with time when loaded in tension as a consequence of sub-critical crack growth effects (Freiman et al. 2009). Because of the characteristic differences in surface defects, glass strength is not a pure material constant.

Frequently used in the built environment, glass is mainly considered an architectural feature that provides occupants with daylight and views while protecting against the weather. Also, the material has, due to its transparent nature, gained an increasing interest in the design of load-bearing structures (see e.g. Snijder 2004; Stein et al. 2019). Mostly being included in the outer envelope of a building, it has to resist several externally imposed loads; at times also of a more extreme character in the form of extreme weather, ballistic impacts, and blast loads (accidental and man-made). All with a considerably shorter load duration than the usual design static load assumptions.

Not considering such load cases in the glass design might have fatal consequences. For instance, in the unfortunate event of an explosion, such as the Oklahoma City Bombing in 1995 (USA) and the Beirut Port explosion in 2020 (Lebanon), it has been shown that numerous injuries and often deaths can be attributed to flying or falling glass shards (Norville et al. 1999; Rudick and Norville 2000; Sukkarieh et al. 2021). Therefore, mitigating an explosion's effects is crucial. It can 


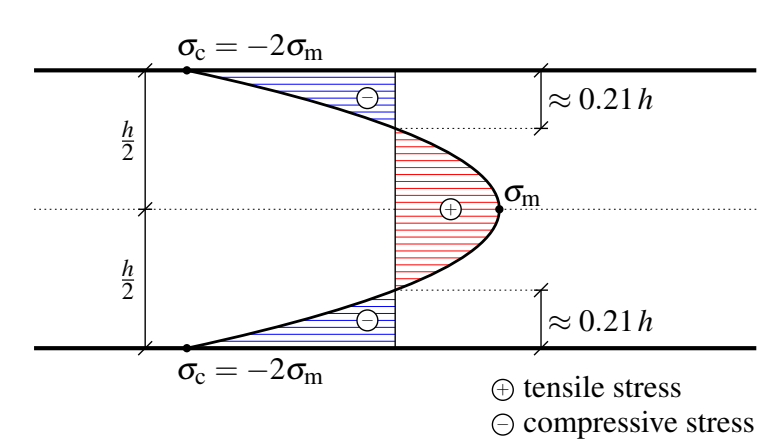

Fig. 1 Symmetric parabolic distribution of residual stresses across the thickness of thermally tempered glass ( $\sigma_{\mathrm{c}}$ is the surface stress; $\sigma_{\mathrm{m}}$ is the mid-plane stress; $h$ is the glass thickness).

be partly met by improving performance of the monolithic glass. For that, several techniques exist to post-process float glass (standard flat glass, also known as 'annealed' glass), which commonly includes thermal treatment (tempering) and/or lamination.

The tempering process, which includes heating and subsequently quenching, strengthens the float glass by introducing a residual stress state with compressive stresses near the surfaces, balanced by tensile stresses in the core. Far from edges, the stress distribution can be assumed to follow a symmetrical parabola, as shown in Fig. 1. The depth of the compressive zone is both analytically and experimentally found to be reasonably good approximated by $21 \%$ of the glass thickness (Nielsen et al. 2021). Failure of thermally tempered glass may be initiated as soon as the compressive surface stress that prevents flaws from opening (i.e. negating the time-dependency) is exceeded, allowing them to grow until the equilibrated residual stress state is disturbed sufficiently. The tempering also causes the glass to fail more safely by fragmenting in small dice due to higher amounts of strain energy release (see e.g. Nielsen et al. 2009; Nielsen and Bjarrum 2017; Pourmoghaddam et al. 2018). Further improvements, in terms of energy absorption and level of protection, can be achieved with lamination that bonds two or more glass panes together by a ductile, transparent plastic interlayer (usually polyvinyl butyral - PVB). In case of glass fracture, the interlayer can deform further, absorbing energy whilst glass fragments adhere to its surface.

The scientific literature has reported numerous studies of laminated glass under blast loading (Hooper et al. 2012; Larcher et al. 2012; Zhang et al. 2013, 2015; Kuntsche 2015; Pelfrene et al. 2016; Del Linz et al. 2017; Angelides et al. 2019; Osnes et al. 2019, 2020). However, the focus was on the interlayer material and the composite interactions in the post-fracture response, while the glass characteristics were less considered at these high strain rates.

In predicting glass failure, strength is an essential parameter to assess. A recent review paper by Meyland et al. (2021c) demonstrates a decisive strain rate sensitivity in the tensile strength of float glass and remarks a lack of data at the high strain rates, e.g. relevant for blast loads. The few experimental studies observing enhanced strength characteristics at strain rates above $1 \mathrm{~s}^{-1}\left(\approx 7 \cdot 10^{4} \mathrm{MPas}^{-1}\right)$ were performed by Peroni et al. (2011), König (2012), Zhang et al. (2012), and Meyland et al. (2019). While Peroni et al. and Zhang et al. performed diametral compression tests on cylindrical specimens in a split-Hopkinson pressure bar (SHPB) setup, König and Meyland et al. employed a high-speed universal testing machine to study flat glass in pure tension and equibiaxial bending, respectively. However, limited data is found to report how the residual stress state in thermally tempered glass affects the tensile strength when loaded at high strain rates (König 2012; Kuntsche 2015; Förch 2019). Furthermore, little has been undertaken to investigate the stiffness of soda-lime-silica glass at various loading rates. The data available indicates that no sensitivity to strain rate is present (Meyland et al. 2021c).

The flexural behaviour of soda-lime-silica glass, such as surface strength and stiffness, at high strain rates remains an open research topic and thus is the focus of the present paper. Both annealed and thermally tempered glass were also studied to include the effect of residual stresses. In the experiments, as-received circular flat glass samples were loaded in a small ring-on-ring test configuration arranged in a modified SHPB setup for the high strain rate tests. The modifications enabled the application of high-speed cameras for fracture assessment and non-contact out-of-plane displacement measurements using stereo digital image correlation (stereo-DIC). For tests at moderate strain rates (quasi-static loading), a universal testing machine was used with the same ring-on-ring test configuration.

\section{Experimental details}

\subsection{Glass samples}

For this study, circular float glass samples of soda-lime-silica were produced with a nominal thickness of $3 \mathrm{~mm} \pm 0.2 \mathrm{~mm}$ and a diameter of $45 \mathrm{~mm} \pm 0.5 \mathrm{~mm}$. After the cut-out of the samples, the manufacturer seamed the edges to remove sharp burrs and secure safe handling of them. The surfaces remained unmachined, and thus in the following, the term asreceived will be used. Also, utilising UV light, each sample's air-side was identified and marked, securing that strength tests were performed for identical surface conditions, the air-side.

The chemical elemental composition of the glass was checked using a scanning electron microscope (SEM) together with energy-dispersive X-ray spectroscopy (EDS). As expected, Table 1 shows that the measured composition (in Oxide \%) is according to the European Standard EN 572-1 (2012). 
Table 1 The chemical elemental composition (in Oxide \%) for the sodalime-silca glass measured using a scanning electron microscope (SEM) together with an energy-dispersive X-ray spectroscopy (EDS) compared to the values prescribed by the European Standard EN 572-1 (2012).

\begin{tabular}{lcccccc}
\hline [Oxide \%] & $\mathrm{SiO}_{2}$ & $\mathrm{CaO}$ & $\mathrm{Na}_{2} \mathrm{O}$ & $\mathrm{MgO}$ & $\mathrm{Al}_{2} \mathrm{O}_{3}$ & Others \\
\hline SEM/EDS & 74.0 & 8.5 & 12.8 & 4.0 & 0.5 & 0.2 \\
EN 572-1 & $69-74$ & $5-14$ & $10-16$ & $0-6$ & $0-3$ & $0-5$ \\
\hline
\end{tabular}

Some of the received samples were thermally tempered to include the effect of residual stresses in the high strain rate investigations. In the tempering process, the samples' orientation was chosen so that the tin-side was in contact with the rollers, leaving the air-side to the air. Following the linear relationship between the mid-plane tensile stress and the cooling rate in the quenching (engine power in \%), as reported by Pourmoghaddam and Schneider (2019), the tempered glass samples were ordered in four different quenching levels to obtain a great variability in the study: $25 \%, 50 \%$, $75 \%$, and $100 \%$. The achieved compressive surface stresses are reported in more detail in Sec. 2.1.1.

The dimensions of all samples were recorded using a digital vernier calliper. All diameters were in agreement with the ordered specifications. The measured thicknesses varied between $3.08 \mathrm{~mm}$ and $3.14 \mathrm{~mm}$ with a mean of $3.11 \mathrm{~mm}$, without any influence of the tempering process being apparent. Further, the measured range show that the float glass producer utilised the upper bound of the allowable tolerance to the nominal thickness prescribed by the European Standard EN 572-2 (2012), which is opposite to what is reported by Schneider (2001). In the evaluation of experimental results presented in Sec. 3, the actual thickness of each sample is used.

\subsubsection{Measurement of the compressive surface stress}

The SCALP-05, a Scattered Light Polariscope from GlasStress Ltd., Tallinn, Estonia, was used to measure the compressive surface stress, $\sigma_{\mathrm{c}}$, in the glass samples. In short, the principle of the SCALP is to measure the retardation of an inclined laser beam sent through the thickness of the glass. Due to the material's photoelastic effect, the retardation of the laser beam varies with strains and thereby stresses in the plane perpendicular to the direction of the beam. A cubic function is often used to fit the retardation profile, and by differentiation, stresses are obtained following a parabolic function as sketched in Fig. 1. For more details, the reader may refer to Aben and Guillemet (1993) and Anton (2015).

Using the SCALP, the derivative of the measured retardation of the laser beam, $\delta$, includes two stress components, $\sigma_{x}$ and $\sigma_{y}$ (Anton 2015):

$\frac{1}{C} \frac{\mathrm{d} \delta(\eta)}{\mathrm{d} \eta}=\sigma_{x}-\sigma_{y} \cos ^{2} \alpha$

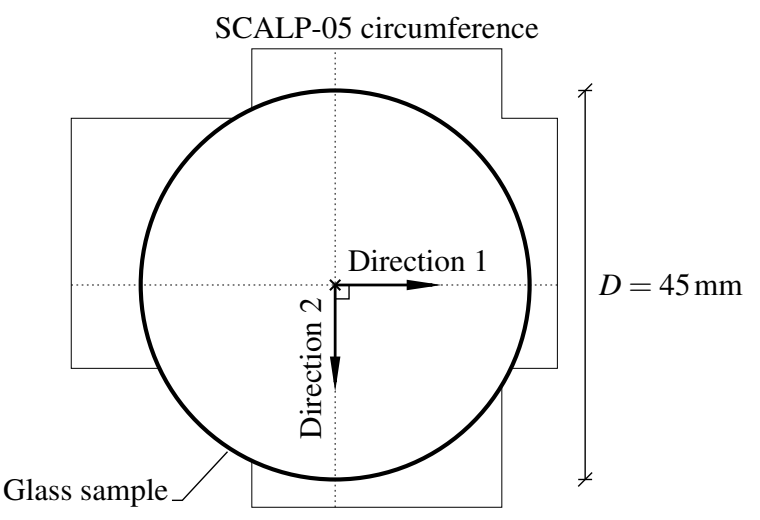

Fig. 2 A sketch of the two directions, perpendicular to each other, used to measure the residual stresses in the centre of the glass samples with the SCALP-05.

Here, $C$ denotes the photoelastic constant, $\eta$ is the coordinate along the laser beam, and $\alpha$ is the beam inclination, which in the used SCALP-05 is $72^{\circ}$. Performing a measurement far away from edges, one may assume an equibiaxial stress field, i.e. $\sigma_{x}=\sigma_{y}=\sigma$, for which Eq. (1) reduces to the following:

$\frac{1}{C} \frac{\mathrm{d} \delta(\eta)}{\mathrm{d} \eta}=\sigma \sin ^{2} \alpha$

However, since it was presumed that the thermal tempering of the small glass samples did not result in a stress field that was perfectly equibiaxial, two orthogonal measurements were required to obtain $\sigma_{x}$ and $\sigma_{y}$ from Eq. (1). These were chosen to originate from the sample centre on the air-side, as illustrated in Fig. 2, providing the most accurate measurement of the surface stress due to the crossing of the laser beams at surface level. The rotation of the sample was chosen arbitrarily due to the circular geometry.

Denoting the two measurements $\sigma_{\eta}$ and $\sigma_{\xi}$, a stress separation is performed by equating Eq. (2) with Eq. (1) for each of the two measurements considering orthogonality. Consequently, two analogous equations are found, which can be solved for $\sigma_{x}$ and $\sigma_{y}$, resulting in:

$\sigma_{x}=\frac{\sigma_{\eta}+\sigma_{\xi} \cos ^{2} \alpha}{1+\cos ^{2} \alpha}, \quad \sigma_{y}=\frac{\sigma_{\xi}+\sigma_{\eta} \cos ^{2} \alpha}{1+\cos ^{2} \alpha}$

For the surface stress measurements, a photoelastic constant $C=3.01 \mathrm{TPa}^{-1}$ was used as found by Nielsen et al. (2010). To secure a good optical contact between the SCALP and the glass sample, an immersion liquid with a refractive index similar to glass was applied between the interfaces. A measurement was repeated five times in both directions, and the mean was used for the stress separation with Eq. (3). The results for $\sigma_{x}$ and $\sigma_{y}$ measured on each glass sample's airside (720 samples in total) are shown as box-plots in Fig. 3 together with the distribution of the data.

The measured residual compressive surface stresses vary between $30 \mathrm{MPa}$ and $60 \mathrm{MPa}$. These values are lower than 


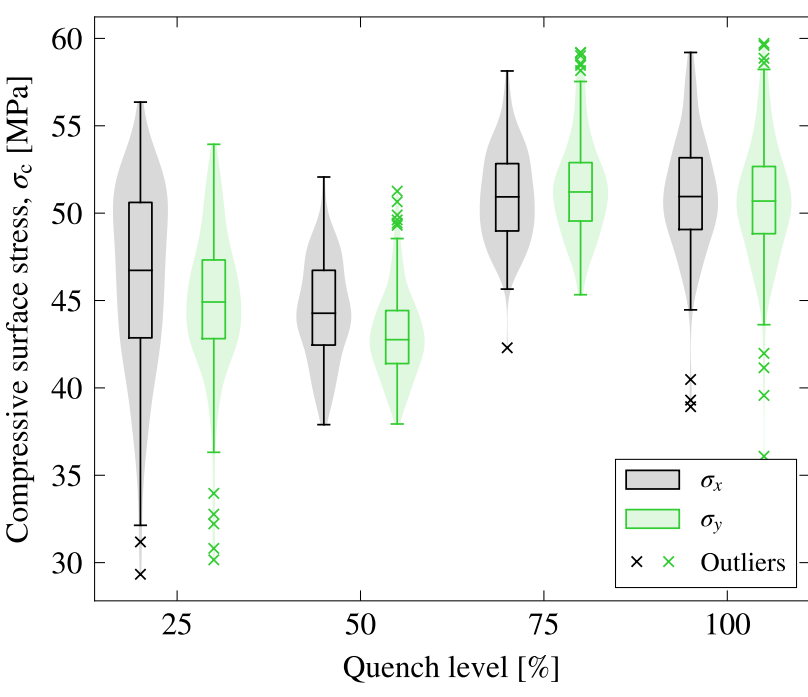

Fig. 3 Box-plot and the distribution of the samples measured compressive surface stresses for the four quench levels after stress separation with Eq. (3).

what is typically expected for fully tempered glass, which according to ISO 20657 (2017) should be minimum $80 \mathrm{MPa}$. For heat-strengthened glass the values should be between $25 \mathrm{MPa}$ and $52 \mathrm{MPa}$ according to ISO 22509 (2020), which covers most of the measured range. Further, a large scatter is seen in the results for each quench level. The reason is difficult to outline since details about the tempering process were unknown to the authors. Nevertheless, some increase in compressive surface stress with quench level is evident, however, not with a linear variation as expected. From the data presented in Fig. 3, increasing the quench level from $25 \%$ to $50 \%$ did not have had a significant enhancing impact on the compressive surface stress. At $75 \%$ a more significant jump is seen, and quenching with $100 \%$ did not enhance further. The unusual tempering behaviour is presumably caused by the small sample geometry that made uniform tempering challenging. Furthermore, comparing $\sigma_{x}$ and $\sigma_{y}$ in the different quench levels, only a slight variation in surface stresses within a sample is present. Hence, the determination of principal stresses using a third measurement in an angle of $45^{\circ}$ to the two other directions was not considered necessary since shear stresses in the glass samples are negligible.

The investigation of the effect of residual stresses at high strain rate loading demands less variation in the compressive surface stress, and therefore another grouping than the quench level was chosen. A minor variation was secured by dividing the thermally tempered glasses into four residual stress (RS) groups, namely RS2 to RS5, using evenly spaced intervals (linear variation between groups). The samples were selected across quench levels based on the minimum measured compressive surface stresses, i.e. $\min \left(\sigma_{x}, \sigma_{y}\right)$. The intervals were chosen to fall within $\sigma_{\mathrm{c}} \pm 1.7 \mathrm{MPa}$ where
Table 2 Statistical evaluation of the minimum measured compressive surface stresses, i.e. $\min \left(\sigma_{x}, \sigma_{y}\right)$, in the five residual stress groups. ( $N$ is the number of samples measured; min is the minimum value; max is the maximum value; $\bar{x}$ is the sample mean; $s_{x}$ is the sample standard deviation)

\begin{tabular}{cccccc}
\hline & $\begin{array}{c}N \\
{[-]}\end{array}$ & $\begin{array}{c}\min \\
{[\mathrm{MPa}]}\end{array}$ & $\begin{array}{c}\max \\
{[\mathrm{MPa}]}\end{array}$ & $\begin{array}{c}\bar{x} \\
{[\mathrm{MPa}]}\end{array}$ & $\begin{array}{c}s_{x} \\
{[\mathrm{MPa}]}\end{array}$ \\
\hline RS1 & 10 & 2.7 & 3.2 & 2.9 & 0.21 \\
RS2 & 86 & 37.9 & 41.2 & 39.9 & 0.91 \\
RS3 & 177 & 42.4 & 45.8 & 43.9 & 1.01 \\
RS4 & 189 & 46.9 & 50.3 & 48.7 & 0.98 \\
RS5 & 81 & 51.4 & 54.6 & 52.7 & 0.87 \\
\hline
\end{tabular}

$\sigma_{\mathrm{c}}=[39.5,44.0,48.6,53.1] \mathrm{MPa}$, which maximised the number of samples in each group. The residual stress group RS1 contains the annealed float glass samples. A statistical evaluation of the compressive surface stress in each residual stress group is provided in Table 2. Data for RS1 are based on measurements on ten float glass samples; more samples support the later investigations. Usually, when designing float glass, it is considered not to have residual stresses. However, the relatively slow cooling in the annealing part of the float glass production leaves a small amount of residual stress, as shown here.

\subsubsection{Etching}

The objective of the present study is to investigate the surface strength of glass. However, testing at the high loading rate caused a more significant number of samples to fail at the edge (a cause for rejection, as discussed in Sec. 3.1) compared to those tested in the universal testing machine at a moderate rate. This behaviour may be explained by the rateinduced strength enhancement, which caused higher loads at which the failure mechanisms began to compete between surface and edge flaws. Therefore, a technique was sought to enhance only the edge quality of some samples. This reduced the total number of tests required to achieve the desired minimum number of valid samples.

Since surface defects govern glass strength, an enhancing effect can be achieved by smoothening or completely removing them. This can be done by etching (see e.g. Kolli et al. 2009; Nielsen et al. 2019). In this study, an etching procedure was developed that only modified the edges without changing the as-received condition of the sample surfaces. Prior to etching, the samples were prepared by first cleaning the surfaces and then covering them centrally using an adhesive foil with a diameter of $42 \mathrm{~mm}$, only leaving approximately $1.5 \mathrm{~mm}$ around the edge uncovered; see Fig. 4(a) and (b). Subsequently, the prepared samples were immersed for $30 \mathrm{~min}$ in a $15-\mathrm{wt} \% \mathrm{NH}_{4} \mathrm{HF}_{2}$ acid aqueous solution (ammonium hydrogen fluoride). The etching produced a clear rim 


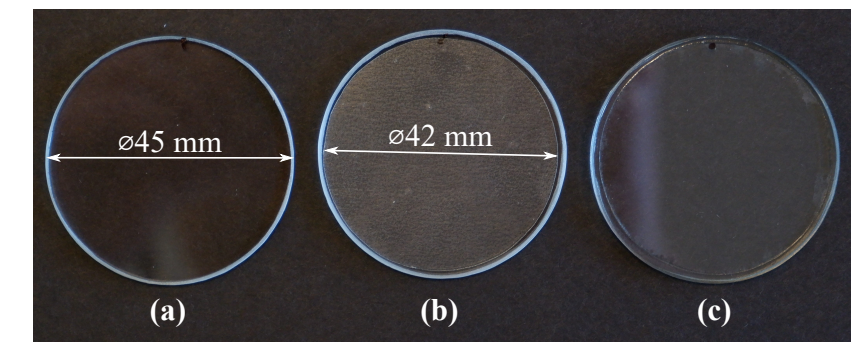

Fig. 4 Image series of a glass sample demonstrating the sample preparation for the etching procedure: (a) the cleaned as-received glass sample, (b) an adhesive foil with a diameter of $42 \mathrm{~mm}$ is applied to both sample surfaces, and (c) the sample after an etching time of $30 \mathrm{~min}$ where a clear rim from the etching is visible.

of removed glass (approx. $60 \mu \mathrm{m}$ depth) on both sides of the samples surrounding the adhesive foil that were removed afterwards; see Fig. 4(c). From the microscope images in Fig. 5, the enhancing effect becomes more visible. Before etching, in (a), the sample edge contained small, sharp defects due to the sanding. Those have been removed or significantly blunted in (b), resulting in a strengthened edge. Thereby the rate of edge failures was reduced from $57 \%$ to $26 \%$.

\subsection{Strength test}

In a previous study (Meyland et al. 2019), the flexural strength of soda-lime-silica glass was investigated using a high-speed universal testing machine. However, some limitations arose at the very high loading rates. The used load cell started ringing at some point, making reliable measurements difficult.

The present study accommodated these challenges by employing a modified SHPB setup, a well-established experimental practice for dynamic material characterisation (Chen and Song 2011). The modifications included a ring-on-ring test configuration for equibiaxial flexural loading of circular flat glass samples. This load configuration was chosen to minimise stressing of the sample's edge where more severe defects are located due to cutting, causing reduced strengths. With maximum stresses in the sample centre, the likelihood of edge failures was reduced, providing a more reliable surface strength measure. The integration of a ring-on-ring test configuration was inspired by Nie et al. (2010) who investigated borosilicate glass at high loading rates. Here, a flat sample was sandwiched between an incident bar and a transmission bar (the original SHPB design), hiding a significant part of the sample's surfaces. However, when testing materials at high loading rates, the application of high-speed cameras is of interest, which in the original SHPB design is limited. Therefore, the novel SHPB setup was subjected to further modifications to ensure an unobstructed view of the sample's tensile surface by replacing the transmission bar with a tube through which the incident bar passes; see illustration in Fig. 6. All design details and the experimental
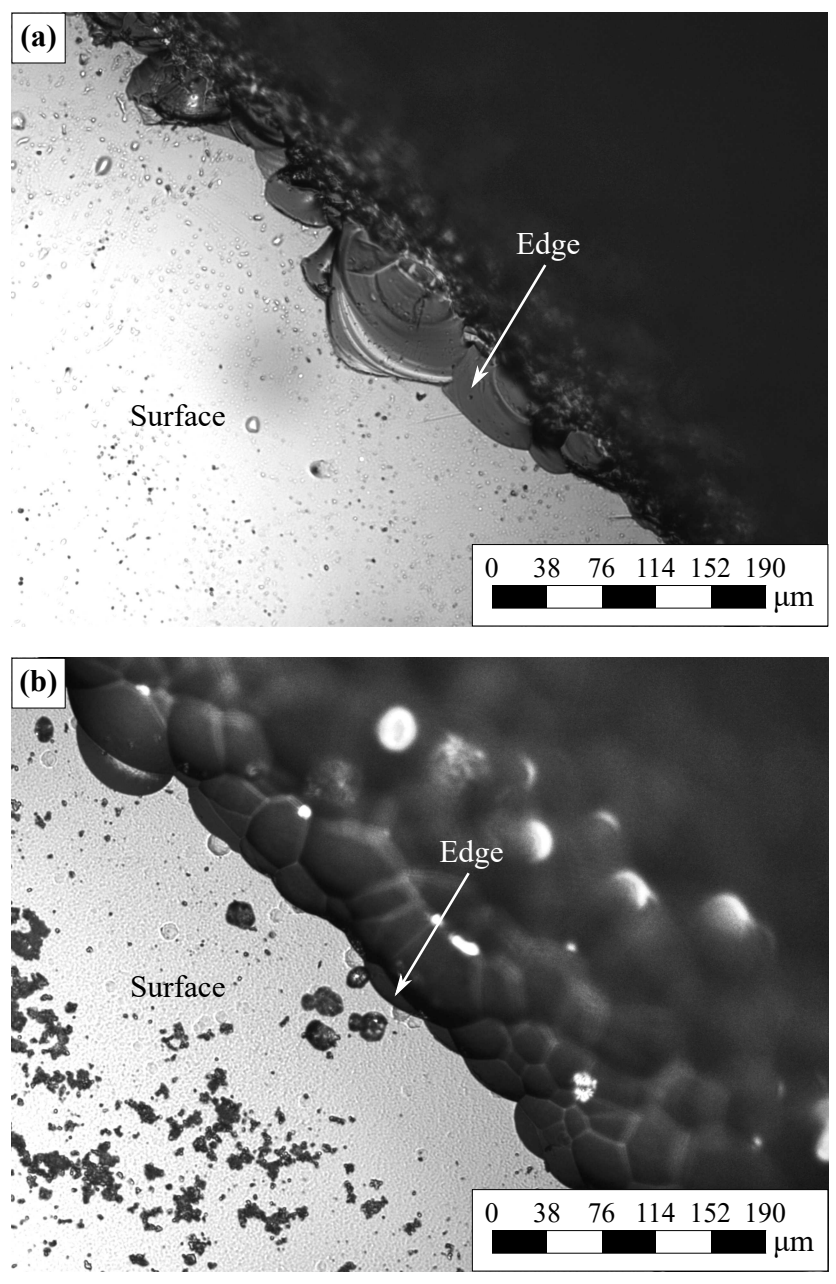

Fig. 5 The effect of etching the sample edge with $\mathrm{NH}_{4} \mathrm{HF}_{2}$ after $30 \mathrm{~min}$ (the microscope images are not taken at the same location): (a) before etching, and (b) after etching.

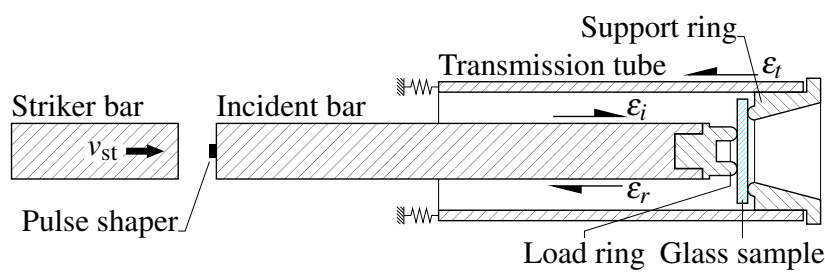

Fig. 6 A schematic representation (cut-view) of the modified splitHopkinson pressure bar setup employed in the present study and reported in detail in Meyland et al. (2021a).

techniques are reported in detail in Meyland et al. (2021a). A short outline is given here.

The introduced ring-on-ring test configuration is a pair of concentric rings that were designed according to the international Standard ASTM C1499-15 (2015). The load ring was mounted to the incident bar, and the support ring with a conical through-going hole to the transmission tube, exposing approx. $54 \%$ of a glass sample's tensile surface. Both rings were produced with a tip radius of $2.5 \mathrm{~mm}$, and their respec- 
tive contact diameters were $18 \mathrm{~mm}$ and $38 \mathrm{~mm}$. The incident bar was produced with a diameter of $30 \mathrm{~mm}$ and the transmission tube with an external diameter of $55 \mathrm{~mm}$ having a wall-thickness of $3.5 \mathrm{~mm}$. All setup parts, that is, the bar, the tube, and the rings, were made of a high-strength aluminium alloy. The material properties were carefully calibrated and can be taken from Meyland et al. (2021a).

In an experiment, a $500 \mathrm{~mm}$-long striker bar, with the same diameter as the incident bar, was accelerated to approx. $6.0 \mathrm{~m} \mathrm{~s}^{-1}$ before impacting the incident bar. A stress wave was thereby initiated travelling towards the sample, loading it at high strain rates. Part of the wave reflected at the load ring/sample interface, whereas the rest transmitted through the sample into the tube. Consequently, three strain pulses could be identified as indicated by the arrows in Fig. 6 and shown as recorded strain signals in Fig. 7, measured with strain gauges attached to the bar/tube surfaces:

1. the incident pulse, $\varepsilon_{i}$

2. the reflected pulse, $\varepsilon_{r}$, and

3. the transmitted pulse, $\varepsilon_{t}$.

Here, a $1 \mathrm{~mm}$-thick and $3.6 \mathrm{~mm}$ in diameter annealed copper disc pulse shaper placed between the striker and incident bar (see Fig. 6) was used to shape the incident pulse into the desired ramp pulse. In that way, a constant stress rate of approx. $4.2 \cdot 10^{6} \mathrm{MPas}^{-1}$ was secured, providing sufficient time to build up a required dynamic force equilibrium between the load ring and support ring, as will be discussed later.

The experiments at moderate strain rates, i.e. quasi-static loading at a rate of $2.0 \mathrm{MPas}^{-1}$, were performed using a universal testing machine (Instron $8872, \pm 25 \mathrm{kN}$ ). A fixture was built to hold the same pair of concentric rings as in the modified SHPB setup. The desired loading rate was achieved, setting the crosshead speed to approx. $0.18 \mathrm{~mm} \mathrm{~min}^{-1}$. All

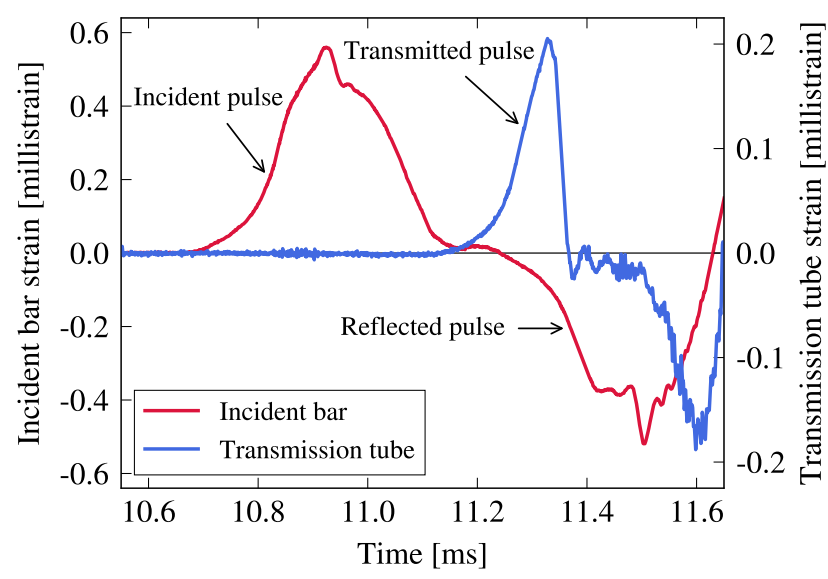

Fig. 7 Example of recorded strain signals on the incident bar and the transmission tube from an experiment with the $500 \mathrm{~mm}$-long striker bar launched at $v_{\mathrm{st}} \approx 6.0 \mathrm{~ms}^{-1}$. samples were equipped with an adhesive strip on the compressive surface to retain the fractured glass in the quasi-static experiments for later assessment.

The temperature of the test environment was $23.4{ }^{\circ} \mathrm{C}$ $\left( \pm 0.4^{\circ} \mathrm{C}\right)$, with a relative humidity of $43.4 \%( \pm 5.2 \%)$.

\subsection{High-speed imaging and non-contact deflection measurements}

The design of the modified SHPB setup enabled the application of two Phantom v2512 high-speed cameras, providing additional details about the glass behaviour under high strain rate loading. The cameras equipped with $100 \mathrm{~mm}$ macro lenses were placed $70 \mathrm{~cm}$ apart from the ring-on-ring test configuration with a mutual angle of approx. $20^{\circ}$ (see Fig. 8). With an image resolution of $256 \times 256$ pixels $^{2}$, sufficient details were captured at a frame rate of 200,000 fps.

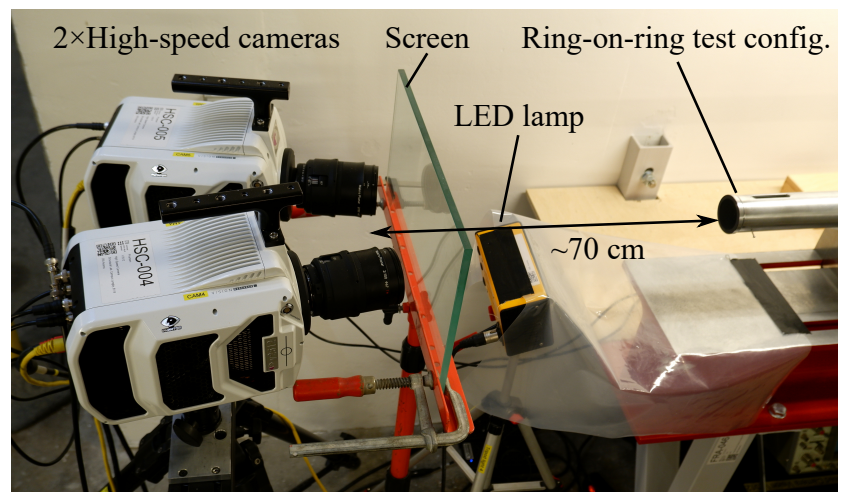

Fig. 8 An image of the two Phantom v2512 high-speed cameras placed in a stereo setup in front of the ring-on-ring test configuration in the modified SHPB setup.

Since it was not an option in the high strain rate experiments to use adhesive foil to retain the fragmented glass samples, the fracture was assessed using high-speed imaging. The cameras were set to acquire images alternately by delaying one camera by $2.5 \mu \mathrm{s}$, resulting in a doubled frame rate without reducing the image resolution. From images, the failure origin was identified, necessary to determine a sample's fracture strength as further discussed in Sec. 3.1. The observed locations of failure origin could be categorised as follows:

(a) within the load ring,

(b) outside the load ring on the surface, and

(c) edge.

Examples for each location are shown in Fig. 9(a)-(c). In (a), the failure originates within the load ring, seen as a black dot/shadow, and from there develops into a radial fracture pattern indicating a pure bending induced failure. Similar 

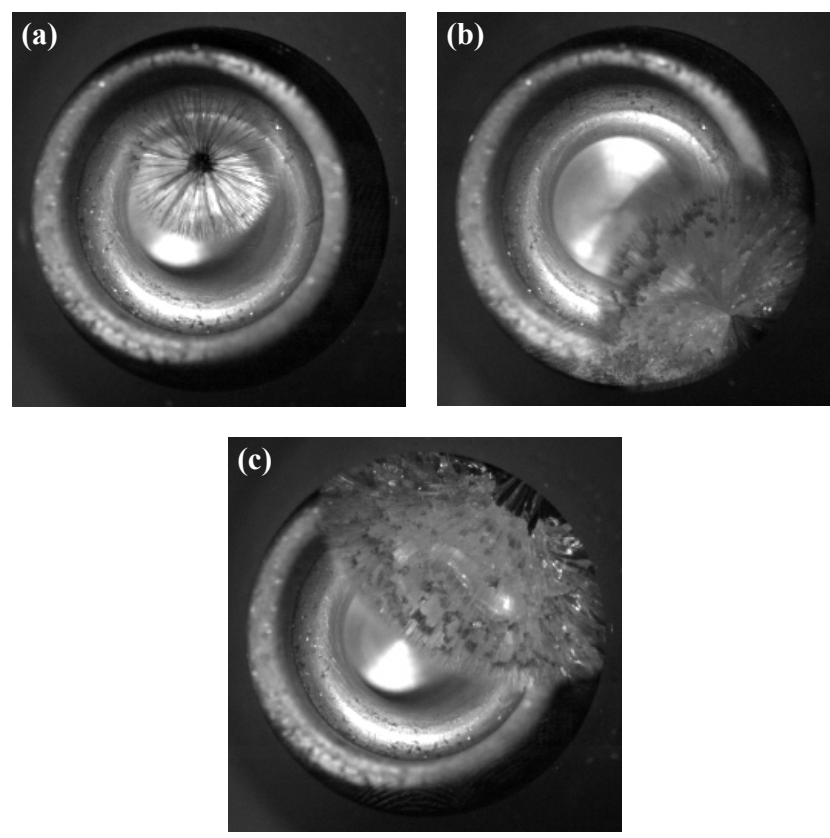

Fig. 9 Examples of the three observed locations of failure origin captured by the use of high-speed cameras at 200,000 fps (on the images the load ring is visible): (a) within the load ring, (b) outside the load ring on the surface, and (c) edge.

appears in (b), however, with an origin outside the load ring but still on the surface. A non-radial fracture pattern is evident in (c), where the failure originates from the sample's edge outside the support ring.

Also, some samples were subjected to deflection measurements using stereo digital image correlation (stereo-DIC) with the software GOM Correlate Pro 2019. It is a noncontact measuring technique that required a unique surface on the glass, which due to its transparency, did not come naturally. Therefore, chalk spray paint was used to create a white ground with black speckles on a sample's tensile surface, having a pattern feature size of approx. 3 to 4 pixels. After a thorough calibration of the two now synchronised cameras, images of the speckled sample surfaces were captured during the dynamic testing using an exposure time of $0.6 \mu \mathrm{s}$. Further, the image acquisition was synchronised with the strain measurements in the modified SHPB setup. The subsequent analysis of the various image series was performed with parameters as listed in Table 3.

In the experiments, the strain gauges on the incident bar and the transmission tube were placed with a distance to the glass sample, which caused a time shift between the captured sample deflection and the associated recorded force histories. In Meyland et al. (2021a), the time shift was experimentally found to equal $305 \mu$ s between the incident bar and the glass sample, whereas it was $150 \mu$ s for the transmission tube.
Table 3 Stereo-DIC analysis parameters.

\begin{tabular}{ll}
\hline DIC software & GOM Correlate Pro 2019 \\
Facet size & $15 \times 15$ pixels $^{2}$ \\
Point distance & 10 pixels \\
Intersection deviation & 0.3 pixels \\
Interpolation & Bi-cubic \\
Calibration deviation & 0.018 pixel \\
Scale deviation & $0.0006 \mathrm{~mm}$ \\
Camera angle & $20.2^{\circ}$ \\
Measuring volume & $35 \times 35 \times 20 \mathrm{~mm}^{3}$ \\
\hline
\end{tabular}

\section{Results and discussions}

The high strain rate characterisation of soda-lime-silica glass comprises an investigation of the material's flexural strength and stiffness (Young's modulus), including the effect of residual stresses. The achieved results are detailed and discussed in the following.

\subsection{Equibiaxial flexural strength}

Equibiaxial flexural strength tests were conducted on glass samples in the five residual stress groups at two stress rates, that is, a quasi-static at $2.0 \mathrm{MPa} \mathrm{s}^{-1}$, and a dynamic at $4.2 \cdot 10^{6}$ $\mathrm{MPas}^{-1}$. At quasi-static loading, the applied load was directly recorded with a load cell in the universal testing machine, whereas dynamically applied load in the modified SHPB setup was determined from strains measured on the incident bar and the transmission tube. With the three pulses identified in the strain measurements, see Fig. 7, and assuming that the strains propagated uniformly over the entire cross-section of the bar and the tube, the resulting force histories on the loading side, $F_{\mathrm{LR}}$, and supporting side, $F_{\mathrm{SR}}$, can be determined as follows:

$F_{\mathrm{LR}}=E A_{\mathrm{IB}}\left(\varepsilon_{i}+\varepsilon_{r}\right)$

and

$F_{\mathrm{SR}}=E A_{\mathrm{TT}} \varepsilon_{t}$

where $E$ is the Young's modulus of the bar/tube material, which in Meyland et al. (2021a) was found to 73.1 GPa, and $A_{\mathrm{IB}}$ and $A_{\mathrm{TT}}$ are the cross-sectional areas of the incident bar and the transmission tube, respectively.

Examples of force histories acquired at a quasi-static and a dynamic loading rate from tests on float glass samples (RS1) are given in Fig. 10. Linear loading up to fracture is evident in both, implying a constant loading rate estimated using the least squares method. Further, the high strain rate experiments determined two force histories held against each other to check the required dynamic force equilibrium, which 


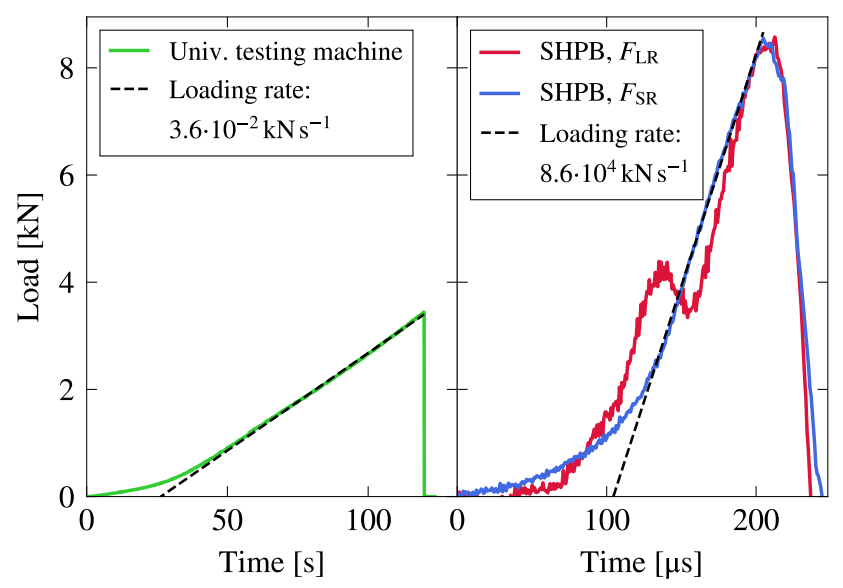

Fig. 10 Examples of force histories achieved in the strength characterisation of untempered float glass samples. A quasi-static loading path is shown on the left, and on the right, a dynamic. In both, the loading rate estimation is exemplified.

successfully is shown here. However, on the loading side minor oscillations are seen in the force history, $F_{\mathrm{LR}}$, which presumably were caused by stress wave reflections in the ring-on-ring test configuration but did not influence the loading of the glass sample (further discussed in Meyland et al. 2021a). Since equilibrium was established in all tests, the force history on the supporting side, the most undisturbed signal, was used to analyse the samples fracture strength.

Failure of brittle materials is often predicted by the Rankine criterion, defining that failure occurs when the maximum principal stress (principal tensile stress), $\sigma_{1}$, at any point reaches a value equal to or larger than the materials apparent tensile strength, $\sigma_{f}$ (see e.g. Samuel and Weir 1999):

$\sigma_{1} \geq \sigma_{f}$

For the glass sample, the maximum principal stresses within the load ring of the ring-on-ring test configuration, which are constant, can be determined analytically from plate bending theory (Timoshenko and Woinowsky-Krieger 1959):

$\sigma_{1}=\frac{3 F}{2 \pi h^{2}}\left[(1-v) \frac{D_{\mathrm{S}}^{2}-D_{\mathrm{L}}^{2}}{2 D^{2}}+(1+v) \ln \frac{D_{\mathrm{S}}}{D_{\mathrm{L}}}\right]$

Here, $F$ is the applied load, $h$ is the glass thickness, $D_{\mathrm{L}}$ is the load ring diameter, $D_{\mathrm{S}}$ is the support ring diameter, $D$ is the sample diameter, and $v$ is the Poisson's ratio of glass (0.23 according to CEN/TS 19100-1 (2021), assuming a rateinsensitivity). With the maximum applied load, i.e. the failure load, Eq. (6) determines according to Eq. (5) the failure stress, $\sigma_{f}$, of a sample, and using a loading rate for $F$ gives a stress rate, $\dot{\sigma}$. Maximum principal strains within the load ring can further be determined using the following relationship valid due to a rotationally symmetrical stress distribution:

$\varepsilon_{1}=\frac{\sigma_{1}}{E_{\mathrm{g}}}(1-v)$ where $E_{\mathrm{g}}$ is the Young's modulus of the glass, equalling $70 \mathrm{GPa}$ according to CEN/TS 19100-1 (2021) being rateinsensitive as reported in Sec. 3.2. Eq. (7) also determines a strain rate, $\dot{\varepsilon}$, in principal direction by inserting a stress rate for $\sigma_{1}$.

The application of Eqs. (6) and (7) requires that failure of a sample originates within the load ring, and usually, those that fail outside are considered not valid. In the present study, all edge failures were excluded since the aim was to investigate the glass' surface strength. Samples that failed between the load ring and the edge were still included as they could measure the surface strength using the exact location of the failure origin, which was estimated from the fractured samples. Based on the location, failure stress and also strain rate was reduced according to the rotationally symmetric stress/strain distributions given in Fig. 11, which were determined from an axisymmetric FE-model in ABAQUS/Standard 2021 using 3-node quadratic shell elements (SAX2) and normalised with Eqs. (6) and (7), respectively. The difference, seen after the load ring, between the distributions of the maximum principal stresses and the maximum principal strains is due to the material's Poisson's ratio.

The flexural strength of the soda-lime-silica glass was determined for the samples' air-side. In each residual stress group, 30 samples were tested at each loading rate, and a minimum of 15 valid samples (surface failure either within or outside the load ring) was the set goal in this study. However, at dynamic loading this goal was not met for RS4, which is why the number of samples was increased with five. Furthermore, additional two samples from the stereo-DIC measurements were added to each residual stress group, and some samples' edges were enhanced using an acid solution to increase the success rate at dynamic loading as described

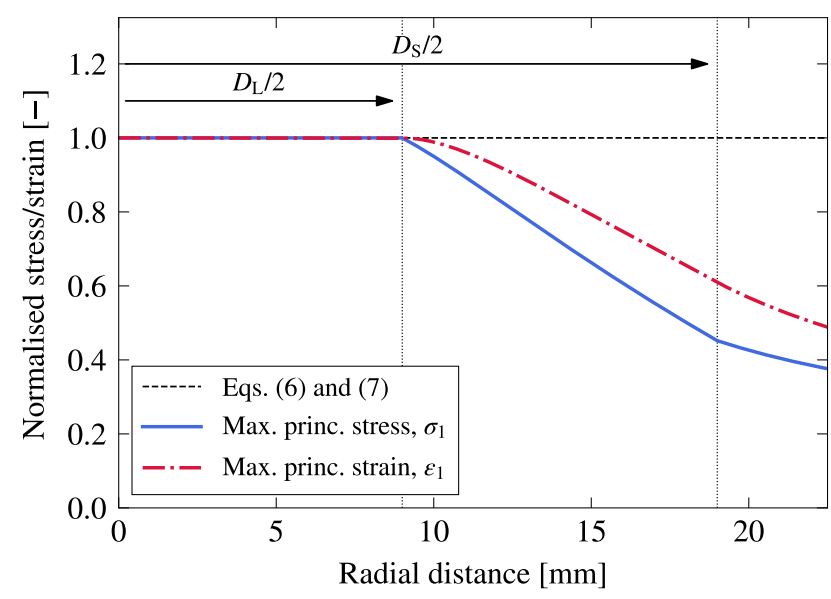

Fig. 11 Rotationally symmetric distribution of maximum principal stresses and strains (numerically determined and normalised with Eqs. (6) and (7)) in a glass sample loaded in the ring-on-ring test configuration. 

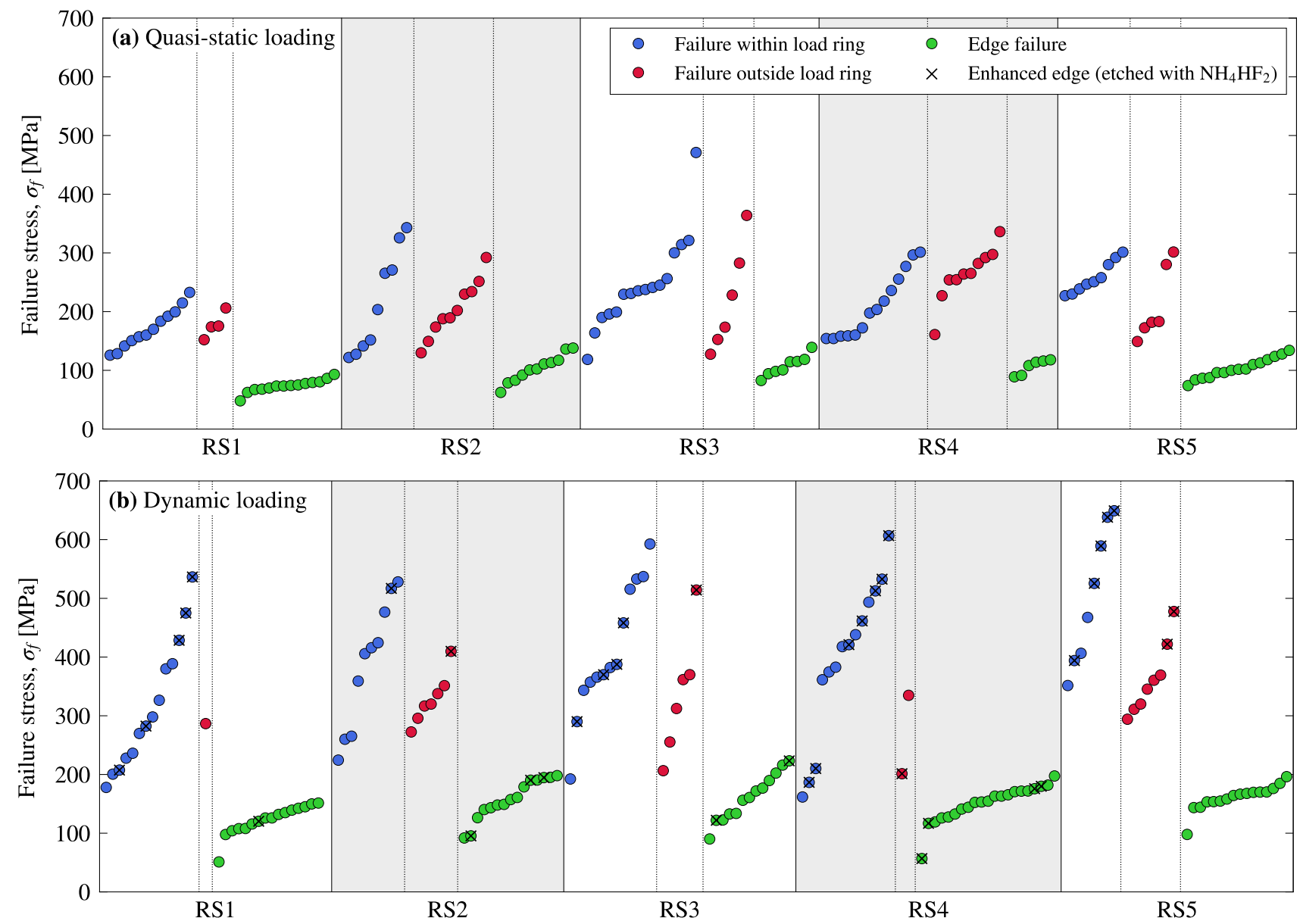

Fig. 12 The individual measured failure stresses of the tested samples in the five residual stress groups, categorised in the three identified locations of failure origin: (a) quasi-static loading and (b) dynamic loading.

in Sec. 2.1.2. The individual measured failure stresses, categorised in the three identified locations of failure origin, are summarised in Fig. 12(a) and (b) for both loading rates. The samples with enhanced edges are marked with a cross.

Expectedly, remarkable lower strengths are seen for the samples that failed at the edge compared to those that failed on the surface. Some samples also failed at the edge when loaded at high strain rates despite having enhanced edges. However, the chance of edge failure was reduced, increasing the number of valid samples. Furthermore, the individual strength measurements reveal that samples with a failure origin outside the load ring are a sound supplement to those that failed within since obtained failure stresses have comparable magnitudes within the different residual stress groups. Also, enhancing the edge strength of some samples in the dynamic tests did not alter the measured surface strengths. The obtained strength data are spread across the existing scatter with no significantly jump. Since the edge strength was enhanced, more samples failed on the surface, some at higher stresses. Those would not have been measured without an enhancement, as the applied load most probably might have caused an edge failure instead.

A complete summary of the equibiaxial flexural strength characterisation of soda-lime-silica glass, based on samples categorised as valid, is provided in Table 4. The stress and strain rates only show a minor variation between residual stress groups. Hence nearly identical loading conditions can be concluded, making a direct comparison feasible within the two loading rates. Furthermore, flexural strength is observed to be affected by compressive surface stress and loading rate, however, with a significant scattering, as also seen from Fig. 12. At quasi-static loading, the standard deviation ranges from 18 to $34 \%$ of the mean values, and from 25 to $35 \%$ at dynamic loading. These ranges are similar to what is reported by Swab et al. (2014), and Meyland et al. (2019) for as-received soda-lime-silica glass, thus considered reasonable. Since the scattering of the strength results reflects the variation of flaw sizes present on the tested glass surfaces, a reduction could have been achieved by applying a wellcontrolled, uniform surface condition. Either by introducing flaws of known size, or removing the present processing or 
Table 4 Summary of the equibiaxial flexural surface strength characterisation of soda-lime-silica glass tested at two loading rates, a quasi-static and a dynamic. Data for the five residual stress groups RS1 to RS5 includes the number of samples and the means of the stress rate, strain rate, and failure stress. In parentheses, the standard deviation to each value is given.

\begin{tabular}{|c|c|c|c|c|c|c|c|c|}
\hline & \multicolumn{4}{|c|}{ Quasi-static loading } & \multicolumn{4}{|c|}{ Dynamic loading } \\
\hline & $\begin{array}{l}N \\
{[-]}\end{array}$ & $\begin{array}{l}\dot{\sigma} \\
{\left[\mathrm{MPas}^{-1}\right]}\end{array}$ & $\begin{array}{l}\dot{\varepsilon} \\
{\left[\mathrm{s}^{-1}\right]}\end{array}$ & $\begin{array}{l}\sigma_{f} \\
{[\mathrm{MPa}]}\end{array}$ & $\begin{array}{l}N \\
{[-]}\end{array}$ & $\begin{array}{l}\dot{\sigma} \\
{\left[\mathrm{MPas}^{-1}\right]}\end{array}$ & $\begin{array}{l}\dot{\varepsilon} \\
{\left[\mathrm{s}^{-1}\right]}\end{array}$ & $\begin{array}{l}\sigma_{f} \\
{[\mathrm{MPa}]}\end{array}$ \\
\hline RS1 & $16 / 30$ & $2.0( \pm 0.2)$ & $2.2 \cdot 10^{-5}\left( \pm 0.1 \cdot 10^{-5}\right)$ & $173( \pm 30.7)$ & $16 / 32$ & $4.1 \cdot 10^{6}\left( \pm 0.8 \cdot 10^{6}\right)$ & $45( \pm 8.7)$ & $324( \pm 110)$ \\
\hline $\mathrm{RS} 2$ & $19 / 30$ & $1.9( \pm 0.3)$ & $2.2 \cdot 10^{-5}\left( \pm 0.3 \cdot 10^{-5}\right)$ & $210( \pm 67.7)$ & $17 / 32$ & $4.1 \cdot 10^{6}\left( \pm 0.6 \cdot 10^{6}\right)$ & $47( \pm 5.3)$ & $364( \pm 91)$ \\
\hline $\mathrm{RS} 3$ & $22 / 30$ & $2.0( \pm 0.3)$ & $2.2 \cdot 10^{-5}\left( \pm 0.2 \cdot 10^{-5}\right)$ & $240( \pm 81.2)$ & $19 / 32$ & $4.4 \cdot 10^{6}\left( \pm 0.8 \cdot 10^{6}\right)$ & $49( \pm 7.9)$ & $387( \pm 113)$ \\
\hline RS4 & $24 / 30$ & $2.1( \pm 0.2)$ & $2.3 \cdot 10^{-5}\left( \pm 0.2 \cdot 10^{-5}\right)$ & $232( \pm 57.0)$ & $16 / 37$ & $4.2 \cdot 10^{6}\left( \pm 0.9 \cdot 10^{6}\right)$ & $47( \pm 9.5)$ & $381( \pm 133)$ \\
\hline RS5 & $15 / 30$ & $2.0( \pm 0.2)$ & $2.3 \cdot 10^{-5}\left( \pm 0.2 \cdot 10^{-5}\right)$ & $240( \pm 49.0)$ & $16 / 32$ & $4.5 \cdot 10^{6}\left( \pm 0.4 \cdot 10^{6}\right)$ & $51( \pm 3.8)$ & $433( \pm 115)$ \\
\hline
\end{tabular}

$N$ : Number of samples (valid/total tested)
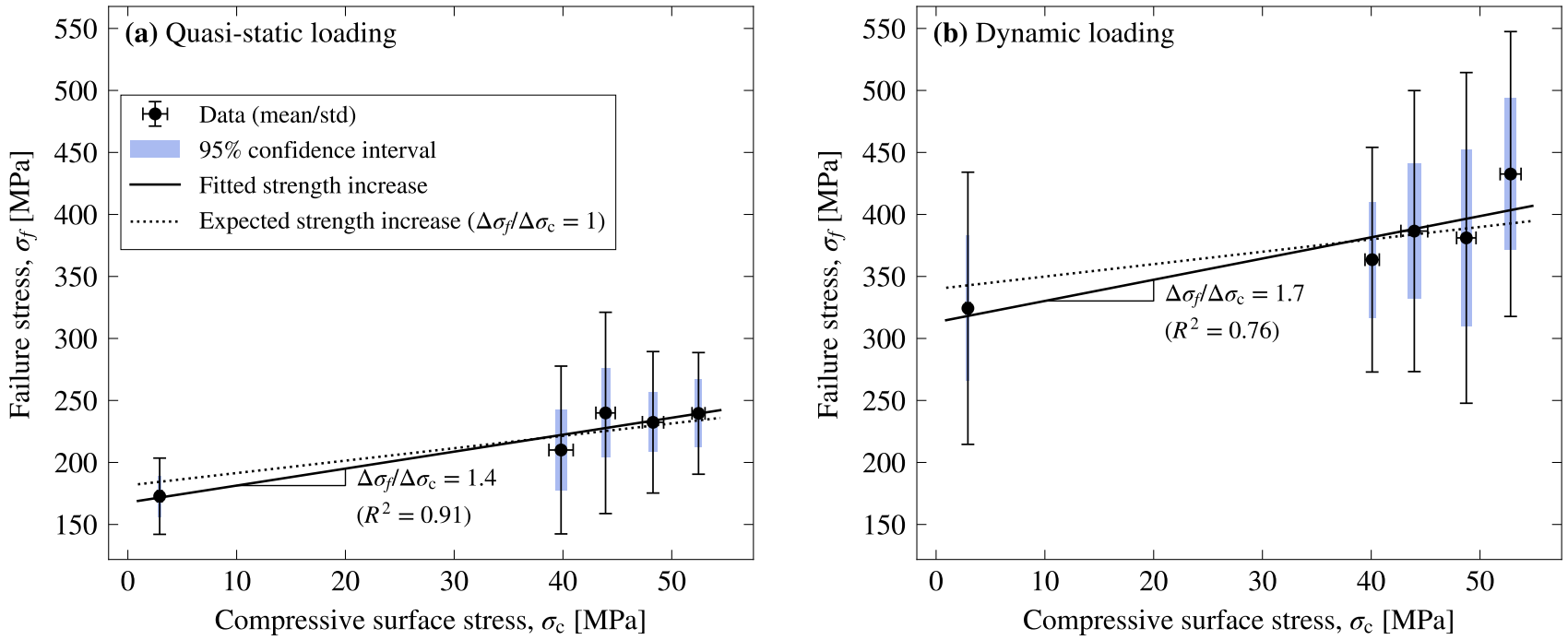

Fig. 13 The measured failure stress, $\sigma_{f}$, of the soda-lime-silica glass as a function of the compressive surface stress, $\sigma_{\mathrm{c}}$, for the five residual stress groups RS1 to RS5: (a) quasi-static loading and (b) dynamic loading.

handling flaws by etching (Nie et al. 2010; Meyland et al. 2019). However, the surface condition was kept as-received in this study not to modify the actual glass strength.

As evident from the above, this study considered two parameters that significantly affected the flexural strength of the tested glass, namely residual stress and loading rate. Beginning with the residual stresses, a simplified linear relationship between the apparent equibiaxial flexural strength, $\sigma_{f}$, and the compressive surface stress, $\sigma_{\mathrm{c}}$, can be expressed as (Rodichev et al. 2007):

$\sigma_{f}=\sigma_{\mathrm{i}}+k \sigma_{\mathrm{c}}$

where $\sigma_{\mathrm{i}}$ is the glass' intrinsic material strength, and $k$ is an empirical constant $(k \cong 1)$ determining how strength increases with residual stresses, which also can be written as $\Delta \sigma_{f} / \Delta \sigma_{\mathrm{c}}$. In Fig. 13, the mean failure stress of each residual stress group is plotted against the mean compressive surface stress. The error bars are the standard deviations, and the blue shadowed boxes the $95 \%$ confidence intervals. Despite observing somewhat large standard deviations, as already discussed, and having investigated a small range of compressive surface stresses, a strength increase is evident at both tested loading rates. A line of best fit through the means of the data indicates that the slope, i.e. $\Delta \sigma_{f} / \Delta \sigma_{\mathrm{c}}$, for the glass tested quasi-statically is 1.4 , and 1.7 for the glass tested dynamically. For comparison, the expected slope of 1, fitted to the data points, is also drawn in Fig. 13(a) and (b). Both the fitted and expected line go through the shown $95 \%$ confidence intervals. The deviation to the expected strength increase might be because only tempered glass samples with residual stresses spanning over a narrow range between 40 and $53 \mathrm{MPa}$ were tested, and within each residual stress group a large scattering was present. Thus, fluctuations between the residual stress groups had a more significant impact on the overall strength increase. For example, strength data reported in Schiavonato et al. (2005) also show an increased slope (as high as $k=1.21$ ), but with a less pronounced deviation to 1 because the glass was tested with compressive surface stresses from $40 \mathrm{MPa}$ up to $140 \mathrm{MPa}$. With glass sample di- 
mensions employed in this study, it was challenging going this high in compressive surface stress using the conventional tempering process (see Sec. 2.1.1). Nevertheless, the studied compressive surface stresses could still be shown to affect the glass strength expectedly, both at quasi-static and dynamic loading.

Next, looking at the loading rate dependency of flexural strength, the following relationship derived from the theory of sub-critical crack growth exists (see e.g. Meyland et al. 2021c):

$\sigma_{f}=\beta \dot{\sigma}^{1 /(n+1)}$

where $\beta$ and $n$ are sub-critical crack growth parameters that depend on the flaw characteristics and environmental test conditions, and in a log-log plot the exponent $1 /(n+1)$ is the slope of the data. Usually, a constant value of $n=16$ is a reasonable and conservative assumption for structural design. $\beta$ varies much more; hence, no fixed value can be given.

The double-logarithmic linear relationship provided by Eq. (9) was used to compare results between the five residual stress groups directly. Obtained failure stresses were normalised with respect to a stress, $\sigma_{0}$, interpolated at $\dot{\varepsilon}_{0}=$ $2.86 \cdot 10^{-5} \mathrm{~s}^{-1}\left(=\dot{\sigma}_{0} / E_{\mathrm{g}}\right.$ for $\left.\dot{\sigma}_{0}=2.0 \mathrm{MPa} \mathrm{s}^{-1}\right)$, similar to Meyland et al. (2021c). The normalised data are presented in Fig. 14 and compared with the most recent investigations on soda-lime-silica glass at high strain rates (mentioned in Sec. 1) together with 'other data' from Meyland et al. (2021b).

A significant loading rate dependency can be ascertained for all five residual stress groups. With respect to $\sigma_{0}$, strength increases from 60 to $86 \%$ are determined at an average strain rate of $48 \mathrm{~s}^{-1}$. However, the residual stresses do not show any significant effect on the loading rate dependency of the glass strength, since samples in RS1 show the highest and samples in RS3 the lowest strength increase, with the other groups (RS2, RS4 and RS5) located in between. No dependency was expected either as the compressive surface stresses are superimposed to the glass's intrinsic material strength. After tensile stresses due to bending loading nullify the compressive surface stresses, glass failure is essentially governed by the present surface defects, which must be assumed to have been nearly identical on all samples tested. Thus, similar behaviour in strength increase with loading rate between the tested residual stress groups is shown here. The observed strength increase at these high strain rates can be explained by decreased or even cancelled sub-critical crack growth effects. It is a unique effect for glass where the atomic structure (silica bonds) reacts with moisture from the environment at a crack tip. Combined with constant or slow tensile loading, it causes cracks to grow steadily, leading to a degradation of the fracture strength with time (Freiman et al. 2009). At rapid loading, however, time for the reaction at a crack tip is shortened or even not existing for water molecules to reach a

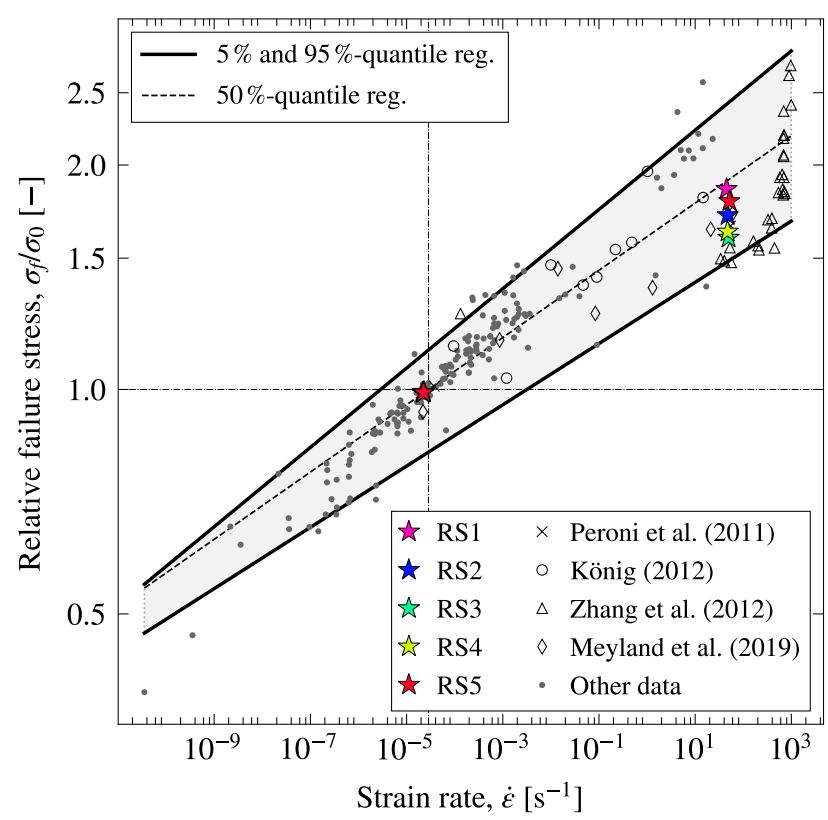

Fig. 14 The relative failure stress, $\sigma_{f} / \sigma_{0}$, of the soda-lime-silica glass as a function of strain rate, $\dot{\varepsilon}$. Additionally, the present study is compared with data from the most recent investigations and 'other data' from Meyland et al. (2021b) for similar test environments, that is, air with a relative humidity between 25 and $67 \%$. The quantile regressions include all data shown.

crack tip, thus delaying or inhibiting the occurrence of crack growth, leading to the observed strength increase.

Comparing the measurements with data from recent studies (Peroni et al. 2011; König 2012; Zhang et al. 2012; Meyland et al. 2019), a good agreement is seen at the tested high strain rate. All strength data are clustered within a narrow range of strain rates with data from Zhang et al. showing the lowest strength increase that furthermore coincides with the plotted $5 \%$-quantile regression. Including the 'other data' from Meyland et al. (2021b) in the comparison, data from the present study seem to deviate from the general trend indicating a beginning levelling of the observed strength increase. Such behaviour aligns with the assertion that the effect of sub-critical crack growth is inhibited at very rapid loading, which at some point will result in a rate-independent strength, i.e. the inert strength of glass. However, the ensuing sudden increase reported by Zhang et al. is debatable, as the plotted data are individual measurements and not mean values as for the other studies.

A further indication of a beginning levelling in the determined strength increases can be found from the slopes of the data, represented by $n$ that results from Eq. (9). Usually, soda-lime-silica glass is conservatively assumed to be well represented by $n=16$. As a further reference, the slope of the $50 \%$-quantile regression in Fig. 14 results in $n=21.2$, and data for the five residual stress groups determines $n$-values 
between 22 and 30 as they are located below the quantile regression. When $n$ is high, it indicates that the chemical reactivity at the crack tip is reduced. Since the obtained values for $n$ are significantly higher than 16 , it is shown that sub-critical crack growth effects were reduced in the present study, confirming the levelling behaviour of the data.

\subsection{The Young's modulus}

Results reported in Meyland et al. (2021a) show that the glass sample deflection in the employed ring-on-ring test configuration is well-described by an analytical plate bending solution, derived from a standard solution in Timoshenko and Woinowsky-Krieger (1959). Hence, the performed noncontact deflection measurements with stereo-DIC provide the determination of the Young's modulus, $E_{\mathrm{g}}$, using a loaddisplacement curve and the following analytical expression:

$$
\begin{aligned}
E_{\mathrm{g}}= & \frac{F}{u} \frac{3\left(1-v^{2}\right)}{8 \pi h^{3}}\left(D_{\mathrm{L}}^{2}+4 r^{2}\right) \\
& {\left[\ln \frac{D_{\mathrm{L}}^{2}}{D_{\mathrm{S}}^{2}}+\frac{D_{\mathrm{S}}^{2}-D_{\mathrm{L}}^{2}}{D_{\mathrm{L}}^{2}+4 r^{2}}\left(1+\frac{\left(D_{\mathrm{S}}^{2}-4 r^{2}\right)(1-v)}{2(1+v) D^{2}}\right)\right] } \\
& \text { for } \quad 0 \leq r \leq \frac{D_{\mathrm{L}}}{2}
\end{aligned}
$$

where $u$ is the deflection at a distance $r$ (within the load ring) from the common central axis of the ring-on-ring test configuration, resulting from the applied load, $F$.

The stiffness investigation was conducted on two samples in each residual stress group, resulting in ten measurements. From the digital image correlation in the software, GOM Correlate Pro 2019, a meshed surface, as exemplified in Fig. 15(a) together with the approximate location of the load ring, was constructed of approx. 480 points at which the glass sample deflection could be evaluated. A contour plot of a full-field deflection measurement is shown in Fig. 15(b) for a load stage corresponding to $5.9 \mathrm{kN}$, from which clearly can be seen that the sample was subjected to an equibiaxial bending at the high strain rate loading. As minor noise was present in the measurements (more in Meyland et al. 2021a), deflection histories were extracted at ten arbitrary chosen points, also highlighted in Fig. 15(a), on each of the ten surfaces in the proximity of the sample centre. After dynamic force equilibrium was checked, the force histories recorded on the supporting side (see example of $F_{\mathrm{SR}}$ in Fig. 10) were matched to the measured deflections by applying the time shift of $150 \mu \mathrm{s}$, corresponding to a shift of 30 images.

A resulting load-deflection curve is plotted in Fig. 16. As expected, the glass shows a linear material response up to the peak load. Thus, a linear regression was performed
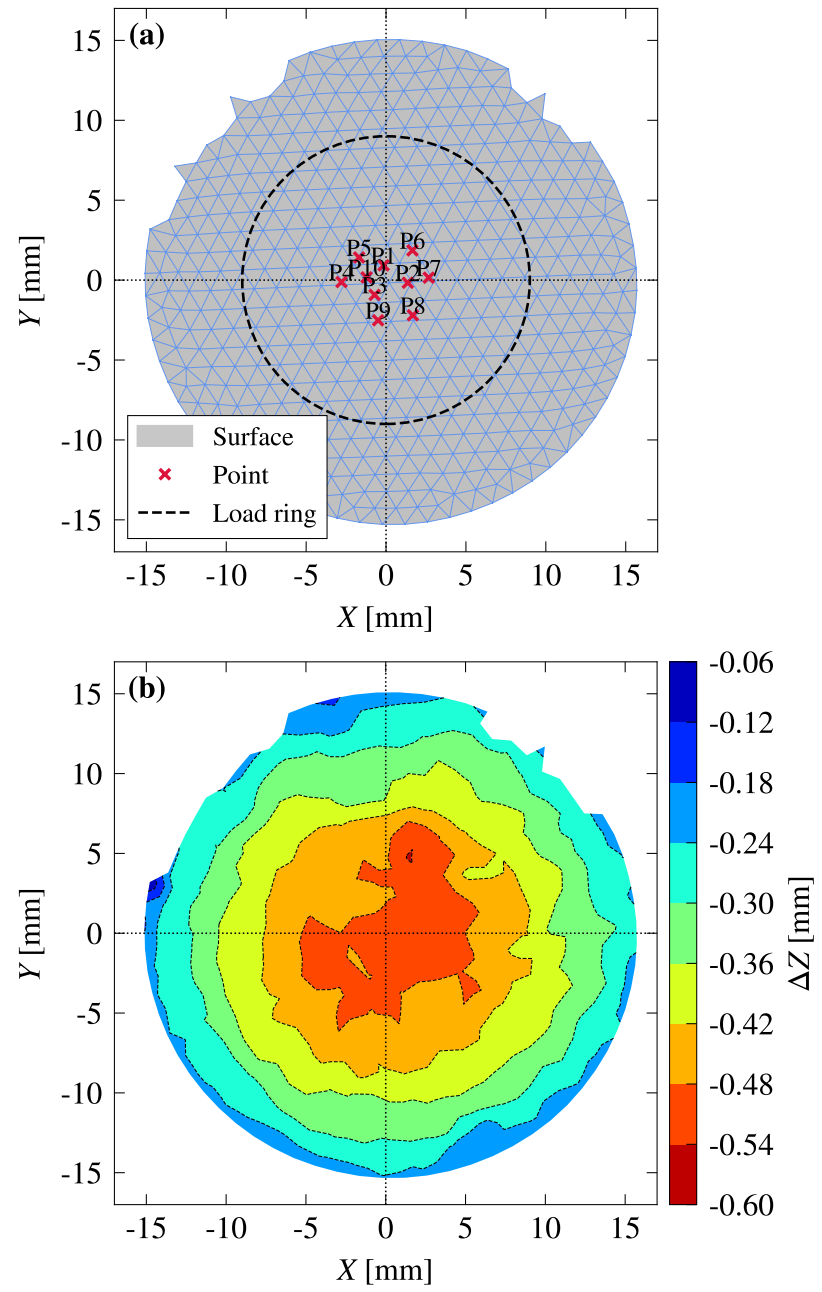

Fig. 15 Results from a stereo-DIC measurement. In (a), a surface component created by the stereo digital image correlation technique and the ten points at which deflection measurements were extracted, and in (b), for the same surface, a contour plot of a full-field deflection measurement, $\Delta Z$, for a load stage corresponding to $5.9 \mathrm{kN}$.

using the least squares method, providing a measure of the Young's modulus as it is proportional to the regression slope, $\Delta F / \Delta u$. With the slope and the exact distance $r$, at which the deflection was extracted on the DIC-generated surface, an estimate for the glass' Young's modulus was determined using Eq. (10). The mean of the ten extracted points per tested sample in each residual stress group is plotted in Fig. 17 with error bars as the standard deviation.

The estimated Young's modulus of the soda-lime-silica glass at high strain rates show minor variations across the residual stress groups, with no indication of being affected by the residual stresses themselves. Both the standard deviation within and the variation between the samples is most likely a result of the noise in the stereo-DIC measurements. However, taking the overall mean, determined as $70.7 \mathrm{GPa}$ $( \pm 2.7 \mathrm{GPa})$, it is in good agreement with the $70 \mathrm{GPa}$ defined 


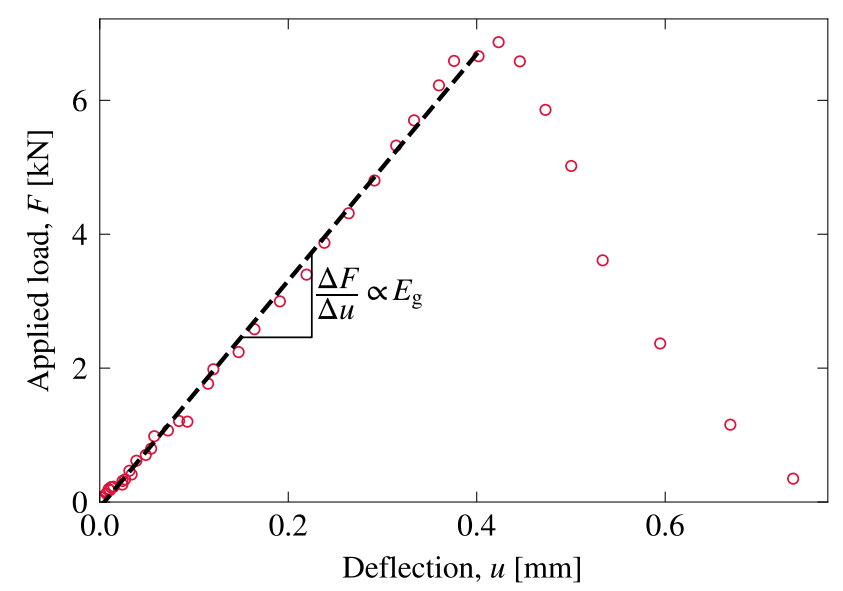

Fig. 16 A load-deflection curve determined from the stereo-DIC measurements exemplified by point 5 from the surface in Fig. 15(a).

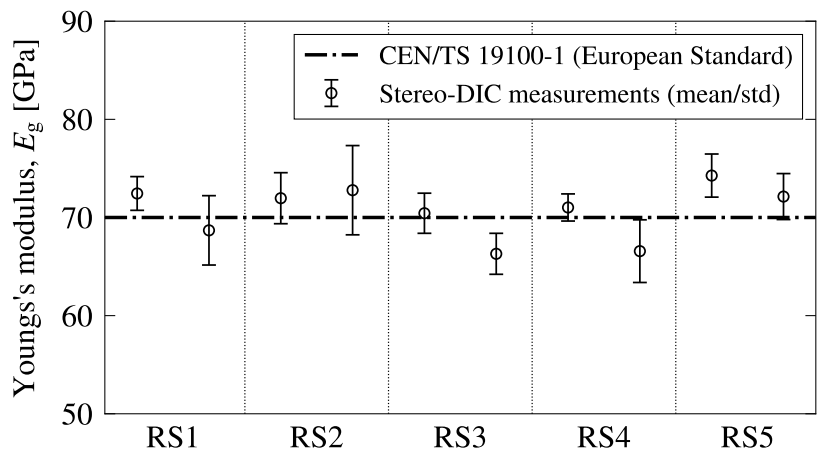

Fig. 17 The Young's modulus, $E_{\mathrm{g}}$, of the glass in the five residual stress groups (RS1 to RS5) determined from the high strain rate experiments using stereo-DIC deflection measurements. For comparison, the value given in CEN/TS 19100-1 (2021) is also shown.

in the European Standard CEN/TS 19100-1 (2021), also plotted in Fig. 17. Thus, the Young's modulus seems not to be loading rate dependent, which also agrees with the findings in Meyland et al. (2021c).

\section{Conclusions}

A ring-on-ring test configuration for equibiaxial flexural loading of small circular flat soda-lime-silica glass samples was successfully integrated into a modified split-Hopkinson pressure bar setup. The modifications in the setup enabled an unobstructed view of a sample's tensile surface, making the application of high-speed cameras possible for fracture assessment and non-contact displacement measurements using the technique of stereo digital image correlation (stereoDIC). Together with a universal testing machine, the glass characteristics, such as strength and stiffness, were investigated on samples with as-received surfaces at two load- ing rates: a quasi-static at $2.0 \mathrm{MPas}^{-1}$, and a dynamic at $4.2 \cdot 10^{6} \mathrm{MPas}^{-1}$. The effect of residual stresses of thermally tempered glass was also considered in the investigations.

The flexural surface strength investigation showed two dependencies. As expected, the strength increased with compressive surface stress within the two tested loading rates. The glass tested at quasi-static loading showed to increase with a slope of 1.4 , whereas the dynamic loading caused a slightly different slope of 1.7. However, it was also shown that the residual compressive surface stress itself did not significantly influence the loading rate dependency of the glass strength. Each tested residual stress group revealed a significant strength increase with loading rate at similar trends. Thus, strength enhancements between 60 and $86 \%$ were found, which furthermore agree with comparable data found in the literature.

Lastly, the performed stereo-DIC measurements determined the stiffness of the glass (the Young's modulus) using analytical plate bending theory. The dynamic experiments across the five residual stress groups could not show any loading rate dependency. Hence, using the $70 \mathrm{GPa}$ for high strain rate loading is considered reasonable.

Acknowledgements This work is funded by the Innovation Fund Denmark (IFD) [grant No. 8053-00088B], Rambøll Fonden [grant No. 201851], and the Danish engineering consultancy Ramboll Denmark A/S, Private \& Public Buildings East. The authors acknowledge Søren P. Kristensen and Hans Exner from Ramboll Denmark A/S for their interest and support given throughout this project. Furthermore, Prof. Jakob B. Wagner and his team from DTU CEN (Center for Electron Nanoscopy) are acknowledged for helping with the SEM/EDS analysis, which detected the studied glass samples' chemical elemental composition.

Conflict of interest The authors declare that they have no known competing financial interests or personal relationships that could have appeared to influence the work reported in this paper.

Data availability The data that support the findings of this study are openly available (licensed under CC BY 4.0, https://creativecommons. $\mathrm{org} /$ licenses/by/4.0/) in the data repository DTU Data, a figshare platform, at https://figshare.com/s/828dd8082a47bc3074cb [private link for review only; a DOI link will be added upon possible publication acceptance].

\section{References}

Aben, H. and Guillemet, C. (1993). Photoelasticity of Glass. Springer Berlin Heidelberg, Berlin, Heidelberg. doi: 10.1007/978-3-64250071-8.

Angelides, S. C., Talbot, J. P., and Overend, M. (2019). The effects of high strain-rate and in-plane restraint on quasi-statically loaded laminated glass: a theoretical study with applications to blast enhancement. Glas. Struct. Eng. doi: 10.1007/s40940-019-00107-4.

Anton, J. (2015). Scattered Light Polariscope SCALP. Instruction Manual (Ver. 5.8.2), GlasStress Ltd., Tallinn, Estonia. 
ASTM C1499-15 (2015). Standard Test Method for Monotonic Equibiaxial Flexural Strength of Advanced Ceramics at Ambient Temperature. ASTM International, West Conshohocken, PA. doi: $10.1520 / \mathrm{C} 1499-15$.

CEN/TS 19100-1 (2021). Design for glass structures - Part 1: Basis of design and materials. European Standard, European Committee for Standardization (CEN), Brussels.

Chen, W. and Song, B. (2011). Split Hopkinson (Kolsky) Bar. Mechanical Engineering Series. Springer US, Boston, MA. doi: 10.1007/9781-4419-7982-7.

Del Linz, P., Hooper, P. A., Arora, H., Wang, Y., Smith, D., Blackman, B. R., and Dear, J. P. (2017). Delamination properties of laminated glass windows subject to blast loading. Int. J. Impact Eng., 105:3953. doi: 10.1016/j.ijimpeng.2016.05.015.

EN 572-1 (2012). Glass in building - Basic soda lime silicate glass products - Part 1: Definitions and general physical and mechanical properties. European Standard, European Committee for Standardization (CEN), Brussels.

EN 572-2 (2012). Glass in building - Basic soda lime silicate glass products - Part 2: Float glass. European Standard, European Committee for Standardization (CEN), Brussels.

Förch, M. (2019). Analysis of Glass Panels Subjected to Blast Load. $\mathrm{PhD}$ thesis, HafenCity University Hamburg, Hamburg, Germany. doi: 10.1007/978-3-662-59087-4.

Freiman, S. W., Wiederhorn, S. M., and Mecholsky, Jr., J. J. (2009). Environmentally Enhanced Fracture of Glass: A Historical Perspective. J. Am. Ceram. Soc., 92(7):1371-1382. doi: 10.1111/j.15512916.2009.03097.x.

Hooper, P., Sukhram, R., Blackman, B., and Dear, J. (2012). On the blast resistance of laminated glass. Int. J. Solids Struct., 49(6):899-918. doi: 10.1016/j.ijsolstr.2011.12.008.

ISO 20657 (2017). Glass in building - Heat soaked tempered soda lime silicate safety glass. International Standard, International Organization for Standardization, Vernier, Geneva, Switzerland.

ISO 22509 (2020). Glass in building - Heat strengthened soda lime silicate glass. International Standard, International Organization for Standardization, Vernier, Geneva, Switzerland.

Kolli, M., Hamidouche, M., Bouaouadja, N., and Fantozzi, G. (2009). HF etching effect on sandblasted soda-lime glass properties. J. Eur. Ceram. Soc., 29(13):2697-2704. doi: 10.1016/j.jeurceramsoc.2009.03.020.

König, C. (2012). Dehnratenabhängigkeit mechanischer Werkstoffkennwerte von Kalk-Natronsilicatglas. $\mathrm{PhD}$ thesis, Technische Universität Carolo-Wilhelmina zu Braunschweig, Germany. doi: 10.24355/dbbs.084-201204230927-0.

Kuntsche, J. K. (2015). Mechanisches Verhalten von Verbundglas unter zeitabhängiger Belastung und Explosionsbeanspruchung. $\mathrm{PhD}$ thesis, Institut für Statik und Konstruktion, Technische Universität Darmstadt, Germany. doi: 10.1007/978-3-662-48831-7.

Larcher, M., Solomos, G., Casadei, F., and Gebbeken, N. (2012). Experimental and numerical investigations of laminated glass subjected to blast loading. Int. J. Impact Eng., 39(1):42-50. doi: 10.1016/j.ijimpeng.2011.09.006.

Meyland, M. J., Bønding, C. K. T., Eriksen, R. N. W., and Nielsen, J. H. (2019). An experimental investigation of the flexural strength of soda-lime-silica glass at high loading rates. Glas. Struct. Eng., 4(2):175-183. doi: 10.1007/s40940-018-0089-2.

Meyland, M. J., Eriksen, R. N. W., and Nielsen, J. H. (2021a). A modified split-Hopkinson pressure bar setup enabling stereo digital image correlation measurements for flexural testing. doi: 10.13140/RG.2.2.30301.33760. Preprint (not peer reviewed).

Meyland, M. J., Nielsen, J. H., and Kocer, C. (2021b). Datasets: Tensile behaviour of soda-lime-silica glass and the significance of load duration - A literature review. DTU Data, Technical University of Denmark. doi: 10.11583/DTU.13655525.
Meyland, M. J., Nielsen, J. H., and Kocer, C. (2021c). Tensile behaviour of soda-lime-silica glass and the significance of load duration A literature review. J. Build. Eng., 44(December):102966. doi: 10.1016/j.jobe.2021.102966.

Nie, X., Chen, W. W., and Templeton, D. W. (2010). Dynamic Ring-on-Ring Equibiaxial Flexural Strength of Borosilicate Glass. Int. J. Appl. Ceram. Technol., 7(5):616-624. doi: 10.1111/j.17447402.2010.02508.x.

Nielsen, J. H. and Bjarrum, M. (2017). Deformations and strain energy in fragments of tempered glass: experimental and numerical investigation. Glas. Struct. Eng., 2(2):133-146. doi: 10.1007/s40940017-0043-8.

Nielsen, J. H., Meyland, M. J., Thorup, B. E., Zugravu, A., and Olesen, J. F. (2019). Investigating the strength effects of drilling in tempered glass. Glas. Struct. Eng., 4(2):243-256. doi: 10.1007/s40940-01900095-5

Nielsen, J. H., Olesen, J. F., and Stang, H. (2009). The Fracture Process of Tempered Soda-Lime-Silica Glass. Exp. Mech., 49(6):855-870. doi: 10.1007/s11340-008-9200-y.

Nielsen, J. H., Olesen, J. F., and Stang, H. (2010). Characterization of the Residual Stress State in Commercially Fully Toughened Glass. J. Mater. Civ. Eng., 22(2):179-185. doi: 10.1061/(asce)08991561(2010)22:2(179).

Nielsen, J. H., Thiele, K., Schneider, J., and Meyland, M. J. (2021). Compressive zone depth of thermally tempered glass. Constr. Build. Mater, 310. doi: 10.1016/j.conbuildmat.2021.125238.

Norville, H. S., Harvill, N., Conrath, E. J., Shariat, S., and Mallonee, S. (1999). Glass-Related Injuries in Oklahoma City Bombing. $J$. Perform. Constr. Facil., 13(2):50-56. doi: 10.1061/(ASCE)08873828(1999)13:2(50).

Osnes, K., Holmen, J. K., Hopperstad, O. S., and Børvik, T. (2019). Fracture and fragmentation of blast-loaded laminated glass: An experimental and numerical study. Int. J. Impact Eng., 132(7491):103334. doi: 10.1016/j.ijimpeng.2019.103334.

Osnes, K., Hopperstad, O. S., and Børvik, T. (2020). Rate dependent fracture of monolithic and laminated glass: Experiments and simulations. Eng. Struct., 212(March):110516. doi: 10.1016/j.engstruct.2020.110516.

Pelfrene, J., Kuntsche, J., Van Dam, S., Van Paepegem, W., and Schneider, J. (2016). Critical assessment of the post-breakage performance of blast loaded laminated glazing: Experiments and simulations. Int. J. Impact Eng., 88:61-71. doi: 10.1016/j.ijimpeng.2015.09.008.

Peroni, M., Solomos, G., Pizzinato, V., and Larcher, M. (2011). Experimental Investigation of High Strain-Rate Behaviour of Glass. Appl. Mech. Mater, 82:63-68. doi: 10.4028/www.scientific.net/AMM.82.63.

Pourmoghaddam, N., Kraus, M. A., Schneider, J., and Siebert, G. (2018). Relationship between strain energy and fracture pattern morphology of thermally tempered glass for the prediction of the 2D macro-scale fragmentation of glass. Glas. Struct. Eng. doi: 10.1007/s40940-01800091-1.

Pourmoghaddam, N. and Schneider, J. (2019). Determination of the engine power for quenching of glass by forced convection: simplified model and experimental validation of residual stress levels. Glas. Struct. Eng., 4(1):117-125. doi: 10.1007/s40940-018-0078-5.

Rodichev, Y., Maslov, V., Netychuk, A., Bodunov, V., and Yevplov, Y. (2007). Bending strength and fracture of glass materials under the different loading conditions. In Glass Performance Days 2007, pages 615-618, Tampere, Finland.

Rudick, M. M. and Norville, H. S. (2000). Discussion and Closure to "Glass-Related Injuries in Oklahoma City Bombing". J. Perform. Constr. Facil., 14(4):167-167. doi: 10.1061/(ASCE)08873828(2000)14:4(167).

Samuel, A. and Weir, J. (1999). Introduction to Engineering Design. Elsevier Butterworth-Heinemann. doi: 10.1016/B978-0-7506-42828.X5000-3. 
Schiavonato, M., Mognato, E., and Redner, A. S. (2005). Stress Measurement, Fragmentation and Mechanical Strength. In Glass Processing Days 2005, pages 92-95, Tampere, Finland.

Schneider, J. (2001). Festigkeit und Bemessung punktgelagerter Gläser und stoßbeanspruchter Gläser. $\mathrm{PhD}$ thesis, Fachbereich Bauingenieurwesen und Geodäsie, Technische Universität Darmstadt, Germany.

Snijder, B. H. H. (2004). Structural Glass and Glass Structures: An Introduction. Struct. Eng. Int., 14(2):72-72. doi: 10.2749/101686604777964071.

Stein, M., Draper, P., and Hellyer, R. (2019). City of Glass: Recent Advancements in Glass Structures in New York City. Struct. Eng. Int., 29(1):101-111. doi: 10.1080/10168664.2018.1519365.

Sukkarieh, G., Lahoud, C., Ghorayeb, R., Abi Karam, M., Succarieh, Y., Saleh, M., and Jalkh, A. (2021). Characteristics of open eye injuries in the Beirut Port explosion. Injury, 52(9):2601-2605. doi: 10.1016/j.injury.2021.07.031.

Swab, J. J., Patel, P. J., Tran, X., Gilde, L., Luoto, E., Gaviola, M. H., Gott, A., Paulson, B., and Kilczewski, S. (2014). Equibiaxial Flexure Strength of Glass: Influence of Glass Plate Size and Equibiaxial Ring Ratio. Int. J. Appl. Glas. Sci., 5(4):384-392. doi: 10.1111/ijag.12094. Timoshenko, S. and Woinowsky-Krieger, S. (1959). Theory of plates and shells. McGraw-Hill, New York, 2. edition.

Zhang, X., Hao, H., and Ma, G. (2013). Parametric study of laminated glass window response to blast loads. Eng. Struct., 56:1707-1717. doi: 10.1016/j.engstruct.2013.08.007.

Zhang, X., Hao, H., and Wang, Z. (2015). Experimental study of laminated glass window responses under impulsive and blast loading. Int. J. Impact Eng., 78:1-19. doi: 10.1016/j.ijimpeng.2014.11.020.

Zhang, X., Zou, Y., Hao, H., Li, X., Ma, G., and Liu, K. (2012). Laboratory Test on Dynamic Material Properties of Annealed Float Glass. Int. J. Prot. Struct., 3(4):407-430. doi: 10.1260/2041-4196.3.4.407. 